\title{
EDITORIAL
}

\section{Some like it cool: hypothermia for newborn infants with hypoxic ischemic encephalopathy}

\section{Journal of Perinatology (2006) 26, 144-146. doi:10.1038/sj.jp.7211458}

To cool or not to cool newborn infants with neonatal encephalopathy following birth asphyxia is one of today's hottest questions in neonatal medicine, close to 50 years since Westin cooled newborn infants suffered birth asphyxia. ${ }^{1}$ This therapy has probably been exercised sporadically the last decades; ${ }^{2}$ however, not in randomized studies. It is well known that chemical reactions are slowed down by reducing the temperature. Intuitively, it therefore should be relatively easy to translate this knowledge and test it out at the bedside. Hypothermia indeed is established in many different scenarios. In adults, induced hypothermia to body temperatures between 32 and $34^{\circ} \mathrm{C}$ improves neurological outcome after cardiac arrest, however, not after trauma or stroke. ${ }^{3,4}$ Why not newborn infants until now? Although the theoretical basis has been there, the finding - some 10 years ago - of a free interval between primary and secondary energy failure following birth asphyxia was important ${ }^{5}$ because that told us that intervention in this free interval, lasting perhaps some hours may reduce brain injury. A prerequisite for these studies has also been the development of different scorings systems that can select quickly and early those children having a poor prognosis who may benefit from cooling. ${ }^{6}$ The development of amplitude electroencephalography (aEEG) also seems as a good tool in refining the selection of risk cases. ${ }^{7}$ Recently, clinical studies have also been published trying to identify early clinical prognostic factors, which may be used to select those newborns that could benefit from hypothermia. ${ }^{8}$

However, randomized clinical trials were not carried out until experimental studies in newborn animals that showed promising effects of both head and total body cooling were published in the 1990s. ${ }^{9-19}$ These animal studies showed that a moderate hypothermia, a reduction of body temperature of $2-4^{\circ} \mathrm{C}$, shortly after hypoxia-ischemia preserves cerebral energy metabolism and reduces cytotoxic edema. Histological changes in the brain as well as functional outcome were also improved.

Moderate hypothermia is associated with bradycardia and elevation of the blood pressure. However, hypotension may also occur, especially in combination with sedation. Hypotension is also observed during rewarming. ${ }^{20}$ Hypothermia to a core temperature of $33^{\circ} \mathrm{C}$ or lower increases the risk of arrhythmia, platelet and coagulation dysfunction, and even sepsis. $^{21}$

\section{A cool brain and a warm heart?}

Some of the larger multicenter ${ }^{22-24}$ as well as some smaller monocentric randomized trials have already been published. ${ }^{25,26}$ Two major strategies have been developed regarding cooling; selective head/brain cooling and total body cooling. Animal studies seem to support both approaches. The Cool Cap study, ${ }^{22}$ which reported the outcome of 234 term infants with moderate or severe neonatal encephalopathy and abnormal integrated electroencephalography (aEEG) randomly assigned infants within $6 \mathrm{~h}$ of birth to either selective head cooling for $72 \mathrm{~h}$ with rectal temperature maintained at $34.5^{\circ} \mathrm{C}$ or conventional care. There was no significant difference in primary outcome (death and/or severe disability at 18 months of age). However, after adjustment for the severity of aEEG changes, odds ratio (OR) for hypothermia treatment was $0.57(0.32-1.01)$. By studying the subgroup with less severe aEEG changes, OR was $0.42(0.22-0.80)$ in favor of hypothermia. In spite of its effect on this subgroup, many still found these results not too convincing, in fact disappointing.

More promising results were published recently by the National Institute of Child Health and Human Development Neonatal Research Network on total body cooling for neonates with hypoxic ischemic encephalopathy, the TOBY trial. ${ }^{23}$ Term or near-term infants with $\mathrm{pH} \leqslant 7.0$, base deficit $\geqslant 16 \mathrm{mmol} / \mathrm{l}$ in umbilical cord or during first hour of life were candidates for enrollment. In case of no biochemical evidence, some clinical criteria were used including a $10 \mathrm{~min}$ Apgar score of 5 or less, or assisted ventilation continued for at least $10 \mathrm{~min}$ after birth. Eligible infants were enrolled within $6 \mathrm{~h}$ after birth and cooled by a blanket reducing the esophageal temperature to $33.5^{\circ} \mathrm{C}$ for $72 \mathrm{~h}$ followed by slow rewarming. There was no difference in survival between the two groups. However, when death and/or moderate or severe disability were combined, risk ratio was $0.72(0.54-0.95)$ in favor of hypothermia. The rate of severe disability among survivors did not differ between the groups.

Magnetic resonance imaging (MRI) changes in infants recruited to the Cool Cap trial and TOBY trial have been analyzed. These preliminary data showed a significant reduction in lesions in the basal ganglia and thalamus region in hypothermic infants. Cortical lesions were not reduced; however cooled infants had fewer major cortical lesions. An effect on cooling assessed by MRI was only seen in those infants with moderate aEEG changes. ${ }^{27}$ Another study found no reduction in basal ganglia injury; however, reduced cortical gray matter abnormalities on MRI in the hypothermic group. ${ }^{28}$ 
In this issue of $J$ Perinatology, Lin et al. ${ }^{29}$ report CT results from a single center study in China, employing selective head cooling. Full-term babies with a 5 min Apgar $<6$, BD $>15 \mathrm{mmol} / \mathrm{l}$ or $\mathrm{pH}<7.10$ in first arterial blood gas, and signs of neonatal encephalopathy were cooled within $6 \mathrm{~h}$, aiming at a rectal temperature of $34-35^{\circ} \mathrm{C}$ for $72 \mathrm{~h}$, or given conventional treatment. Hypothermia significantly reduced abnormal CT findings at the age of 5-7 days, as well as improved the Neonatal Behavioral Neurological Assessment Score at days 7-10. There was no report of death and/or disability in this study. Further, no follow-up was performed. The study included few patients, and there was no strict randomization. Allocation of patients to the two groups according to odd and even dates may be justified in resuscitation studies in the emergency setting, but a true randomization should have been possible to carry out in this study in which enrollment occurred within $6 \mathrm{~h}$. Still the study indicates hypothermia may have some beneficial effect and that this therapy is easy to set up and carry out.

On the basis of these studies it seems clear that moderate hypothermia protects at least moderately affected infants; and on the basis of the randomized studies, it may be tempting to conclude that total body cooling is more efficient than selective brain cooling. To answer such a question, a head to head study comparing these two regimes should, however, be performed.

Where to go from now? Presently, the data according to my opinion are not convincing enough to start routine cooling of asphyxiated babies. We should await the results from ongoing clinical trials before such a therapy is instituted. We have time to wait because the results are not too dramatic anyway. Hypothermia may represent some progress in selected infants but does not so far seem to represent a major breakthrough in preventing postasphyxial brain injury. This view is in line with the recommendation of the 2005 consensus conference on newborn resuscitation, in which it is stated: 'there is insufficient data to recommend the routine use of systemic or cerebral hypothermia after resuscitation of infants with suspected asphyxia. Further clinical trials are needed to confirm that treatment with cooling is beneficial, to identify infants who will benefit most, and to determine the most effective method and timing of cooling, ${ }^{30}$ However, this does not preclude that future protocols may give better results. For instance, if cooling is started earlier and only in highly selected patients, the results may also be even better for the most severely affected infants. Several unsolved questions need to be addressed. I have been wondering how the results would change if resuscitation is carried out with room air instead of $100 \%$ oxygen before hypothermia is initiated. It is now well established that pure oxygen triggers inflammatory and other adverse responses in several organs, as well as in the brain. ${ }^{31,32}$ It therefore could be argued that the randomized trials so far have tested out a nonoptimal protocol. New studies combining room air resuscitation with hypothermia are therefore planned.
In spite of this, moderate hypothermia instituted within $6 \mathrm{~h}$ and carried out for $72 \mathrm{~h}$ with slow rewarming may soon become a routine reality in every tertiary NICU. As shown by Lin et al., ${ }^{29}$ the therapy is easy and not expensive, and if the hypothermia is controlled carefully, not being too deep, it adds few extra risks. We already know that some asphyxiated newborn infants like it cool. However, we do not know exactly who these infants are and what long-term benefits they may get.

OD Saugstad Editor

Department of Pediatric Research, Rikshospitalet University Hospital, University of Oslo, Sognsvannsun, 20, Oslo, Norway E-mail: o.d.saugstad@medisin.uio.no

\section{References}

1 Westin B, Miller Jr JA, Nyberg R, Wedenberg E. Neonatal asphyxia pallida treated with hypothermia alone or with hypothermia and transfusion of oxygenated blood. Surgery 1959; 45: 868-879.

2 Kopshev SN. Craniocerebral hypothermia in the prevention and combined therapy of cerebral pathology in infants with asphyxia neonatorum. Akush Ginekol (Mosk) 1982; 7: 56-58. Russian.

3 Bernard SA, Gray TW, Buist MD, Jones BM, Silvester W, Gutteridge G et al. Treatment of comatose survivors of out- of- hospital cardiac arrest with induced hypothermia. NEJM 2002; 346: 557-563.

4 The Hypothermia After Cardiac Arrest Study Group. Mild hypothermia to improve the neurologic outcome after cardiac arrest. NEJM 2002; $\mathbf{3 4 6}$ : 549-556.

5 Lorek A, Takei Y, Cady EB, Wyatt JS, Penrice J, Edwards AD et al. Delayed ('secondary') cerebral energy failure after acute hypoxia-ischemia in the newborn piglet: continuous $48 \mathrm{~h}$ studies by phosphorus magnetic resonance spectroscopy. Pediatr Res 1994; 36: 699-706.

6 Sarnat HB, Sarnat MS. Neonatal encephalopathy following fetal distress: a clinical and electroencephalographic study. Arch Neurol 1976; 33: 696705.

7 Toet MC, Hellstrom-Westas L, Groenendal F, Eken P, de Vries LS. Amplitude integrated EEG 3 and $6 \mathrm{~h}$ after birth in full term neonates with hypoxicischemic encephalopathy. Arch Dis Child Fetal Neonatal Ed 1999; 81: F19-F23.

8 Saugstad OD, Ramji S, Rootwelt T, Vento M. Response to resuscitation of the newborn: early prognostic variables. Acta Paediatr 2005; 94: 890-895.

9 Towfighi J, Housman C, Heitjan DF, Vannucci RC, Yager JY. The effect of focal cerebral cooling on perinatal hypoxic-ischemic brain damage. Acta Neuropabtol (Berl) 1994; 87: 598-604.

10 Thoresen M, Penrice J, Lorek A, Cady EB, Wylezinska M, Kirkbride V et al. Mild hypothermia after severe transient hypoxia-ischemia ameliorates delayed cerebral energy failure in the newborn piglet. Pediatr Res 1995; 37: 667-670.

11 Thoresen M, Bagenholm R, Loberg EM, Aprencia F, Kjellmer I. Posthypoxic cooling of neonatal rats provides protection against brain injury. Arc Dis Child fetal Neonatal Ed 1996; 74: F3-F9.

12 Haaland K, Loberg EM, Steen PA, Thoresen M. Posthypoxic hypothermia in newborn piglets. Pediatr Res 1997; 41: 505-512. 
13 Bona E, Hagberg H, Loberg EM, Bagenholm R, Thoresen M. Protective effects of moderate hypothermia after neonatal hypoxia-ischemia: short and longterm outcome. Pediatr Res 1998; 43: 738-745.

14 Thoresen M, Simmonds M, Sata S, Tolley J, Silver IA. Effective selective head cooling during posthypoxic hypothermia in newborn piglets. Pediatr Res 2001; 49: 594-599.

15 Gunn AJ, Gunn TR, de Haan HH, Williams CE, Gluckman PD. Dramatic neuronal rescue with prolonged selective head cooling after ischemia in fetal lambs. J Clin Invest 1997; 99: 248-256.

16 Nedelcu J, Klein MA, Aguzzi A, Martin E. Resuscitative hypothermia protects the neonatal rat brain from hypoxic-ischemia in neonatal rats. Brain Pathol 2000; 10: 61-71.

17 Tooley TR, Satas S, Porter H, Silver IA, Thoresen M. Head cooling with mild systemic hypothermia in anesthetized piglets is neuroprotective. Ann Neurol 2003; 53: $65-72$.

18 Shankaran S, Laptook A, Wright LL, Ehrencranz RA, Donovan EF, Fanaroff AA et al. Whole-body hypothermia for neonatal encephalopathy: animal observations as a basis for randomized, controlled pilot study in term infants. Pediatrics 2002; 110: 377-385.

19 Gunn AJ, Gunn TR, Gunning MI, Williams CE, Gluckman PD. Neuroprotection with prolonged head cooling started before postischemic seizures in fetal sheep. Pediatrcs 1998; 102: 1098-1106.

20 Thoresen M, Whitelaw A. Cardiovascular changes during mild therapeutic hypothermia and rewarming in infants with hypoxic-ischemic encephalopathy. Pediatrics 2000; 106: 92-99.

21 Azzopardi D, Robertson NJ, Cowan FM, Rutherford MA, Rampling M, Edwards AD. Pilot study of treatment with whole body hypothermia for neonatal encephalopathy. Pediatrics 2000; 106: 684-694.

22 Gluckman PD, Wyatt JS, Azzopardi D, Ballard R, Edwards AD, Ferriero DM et al. Selective head cooling with mild systemic hypothermia after neonatal encephalopathy: multicentre randomized trial. Lancet 2005; 365: 663-670.
23 Shankaran S, Laptook AR, Ehrenkranz RA, Tyson JE, McDonald SA, Donovan EF. Whole-body hypothermia for neonates with hypoxic-ischemic encephalopathy. NEJM 2005; 353: 1574-1584.

24 Eicher DJ, Wagner CL, Katikaneni LP, Hulsey TC, Bass WT, Kaufman DA et al. Moderate hypothermia in neonatal encephalopathy: efficacy outcomes. Pediatr Neurol 2005; 32: 11-17.

25 Battin MR, Penrice J, Gunn TR, Gunn AJ. Treatment of term infants with head cooling and mild systemic hypothermia (35.0 degrees $\mathrm{C}$ and 34.5 degrees C) after perinatal asphyxia. Pediatrics 2003; 111: 244-251.

26 Debillon T, Daoud P, Durand P, Cantagrel S, Jouvet P, Saizou C et al. Whole-body cooling after perinatal asphyxia: a pilot study in term neonates. Dev Med Child Neurol 2003; 45: 17-23.

27 Rutherford MA, Azzopardi D, Whitelaw A, Cowan F, Renowden S, Edwards AD et al. Mild hypothermia and the distribution of cerebral lesions in neonates with hypoxic-ischemic encephalopathy. Pediatrics 2005; 116: 1001-1006.

28 Inder TE, Hunt RW, Morley CJ, Coleman L, Stewart M, Doyle LW et al. Randomized trial of systemic hypothermia selectively protects the cortex on MRI in term hypoxic-ischemic encephalopathy. J Pediatr 2004; 145: 835-837.

29 Lin Z-L, Yu H-M, Lin L, Chen S-Q, Liang Z-Q, Zhang Z-Y. Mild hypothermia via selective head cooling as neuroprotective therapy in term neonates with perinatal asphyxia: an experience from a single neonatal intensive care unit. J Perinatol 2006; 26: 180-184.

30 International liaison committee on resuscitation, American heart association, and Europen resuscitation council. Neonatal resuscitation. Circulation 2005; 112: III-91-III-99.

31 Munkeby BH, Borke WB, Bjornland K, Sikkeland LL, Borge GI, Lomo J et al. Resuscitation with $100 \% 02$ increases cerebral injury in hypoxemic piglets. Pediatr Res 2004; 56: 783-790.

32 Vento M, Sastre J, Asensi MA, Vina J. Room-air resuscitation causes less damage to heart and kidney than 100\% oxygen. Am J Respir Crit Care Med 2005; 172: 1393-1398. 